\title{
Exploration on Teaching Reform of Environmental Design from the Perspective of Inheriting Regional Culture
}

\author{
Ye Wang* \\ School of Art Design and Media \\ Sanda University \\ Shanghai, China \\ yewang@ sandau.edu.cn
}

\begin{abstract}
In this paper, the significance and the ways of teaching reform of integrating regional culture into the teaching of environmental design have been explored through theoretical analysis and teaching practice. Starting from analyzing the reasons for the problems of the homogeneity of teaching in environmental design and the lack of creative ability of students, the effective way to solve these problems, i.e. to effectively combine the local cultural resources with modern design education, was identified. Based on the analysis, the specific measures of integrating regional culture into the teaching of the environmental design were summarized, such as "expanding curriculum content", "optimizing practice teaching design", "organizing cross-professional project teaching", etc. Moreover, the feasibility and effectiveness of these measures were proved through the practical cases of the teaching reform of environmental design at Sanda University. The results would help to enhance students' awareness of inheriting regional culture and their ability to innovate and design as well as to create specialty programs.
\end{abstract}

Keywords-Regional Culture; Environmental Design; Teaching Reform; Practical Teaching; Inheriting

\section{INTRODUCTION}

Environmental design is a comprehensive and highly applied discipline integrating art, technology and science. Its research and practice focus on the settlement environment, namely city environment and rural environment. As a place and activity center for human settlements, the formation and construction of the settlement environment has significant regional cultural characteristics. Geographical climate characteristics, historical remains, residents' lifestyles, religious beliefs, cultural traditions, folk art and other factors will have an important impact on environmental design, and give the space local characteristics and unique temperament. Therefore, environmental design talents not only need to have solid professional knowledge and professional skills to solve engineering and technical problems, but also are responsible of expressing, inheriting and developing regional culture. At present, while the innovative spirit and practical ability of the students were cultivated in the professional education of environmental design, the modern design education should be also effectively combined with local regional cultural resources.

\section{THE LACK OF CHARACTERISTICS OF ENVIRONMENTAL DESIGN EDUCATION AND ITS CAUSES}

China's environmental design (formerly known as environmental art design) professional education started in the 1980s and flourished with the rapid urbanization process. However, behind the prosperity, environmental design professional education in colleges and universities had the problems of single characteristics, serious homogenization phenomenon and insufficient innovation ability of students.

The first reason which resulted in the above issues was that the design education of many colleges and universities pursues the "contemporaneity" design education excessively. They didn't pay enough attention to the regional culture and make full use of it and didn't seriously explore the most suitable ways for the development of themselves. This resulted in the design teaching mode of many colleges and universities was too identical and conceptualized, and the regional characteristics are not obvious[1]. Second, the applicationoriented talent model of environmental design in China focused on the cultivation of skills and techniques, and the cultivation of students' humanistic quality was mostly superficial. Most of the courses related to traditional culture, regional culture, urban culture and other local cultures in the curriculum system were carried out in the form of public elective courses or lectures and without deep integration with professional education. This made the students' cognition of local culture tended to be superficial and symbolic, lack of in-depth understanding and recognition, and even impossible to inherit and innovate, which was ultimately reflected in the lack of originality, regional cultural connotation and local feelings in their works. At present, China is facing the situation that the urban and rural constructions were similar and the regional characteristics were disappearing. The rejuvenation and reconstruction of regional culture in urban and rural environmental construction has become an important issue faced by designers in the period of transformation and development. At the same time, it is also a problem that environmental design educators who were responsible for training future designers need to think about and pay attention to. 
of professional general education and professional characteristic education can be realized.

\section{CULTURE INTO THE TEACHING OF ENVIRONMENTAL DESIGN}

In China, regional culture generally refers to the cultural tradition with a long history, unique characteristics and still playing a role in a specific region. It is the civilization performance of ecology, folk custom, tradition and habit in a specific region. It merges with the environment in a certain region, so it has a regional brand and unique characteristics. Rich regional cultures are inexhaustible teaching resources for environmental design education in colleges and universities. By infiltrating regional traditional culture into the course construction and teaching processes in various forms, such as subjects, technologies and materials, students' in-depth understanding and perception of regional humanities, technology and art can be improved and the necessity and value of maintaining excellent cultural tradition can be understood. Therefore, the correct cultural value orientation can be established, so that they can have their own evaluation criteria and transformation and absorption ability in the face of various foreign cultural and art thoughts. By taking the regional culture and artistic prototype in their lives as the teaching content and practice theme, it is easier for students to establish an intuitive understanding, construct a knowledge framework, and understand the cultural connotation. Moreover, during the design practice, they can draw nutrients from it and organically combine it with the latest design theories such as sustainable design, service design, social innovation and other advanced technologies such as big data and artificial intelligence to explore the effective way to achieve the inheritance and innovation of regional culture.

Therefore, to reform the curriculum and teaching system and build a relatively scientific and perfect teaching system from theory to practice based on the concept of exploring the organic combination of regional culture and environmental design teaching is not only an effective way to change the current homogenization of environmental design education and the lack of students' innovation ability, but also of great significance to protect and inherit regional culture, develop local design and enhance cultural self-confidence in the period of transformation and development.

\section{WAYS TO INTEGRATE REgIONAL CULTURE INTO THE TEACHING OF ENVIRONMENTAL DESIGN}

Integrating excellent regional culture into teaching is becoming the dominant direction of the teaching reform of environmental design. How to embed the knowledge and design concepts related to regional culture into the whole teaching system is the core issue that should be paid attention to in teaching reform. The guiding ideology for solving this problem should follow these steps: first, to let the students understand and pay attention to the regional culture first, then deeply interpret it and consciously apply it in the design word, and finally try to innovate the design[2]. The specific implementation can be realized by integrating the regional culture gradually into professional teaching through the expanding curriculum content, optimizing practice teaching design and interdisciplinary teaching based on concept of the Macro Design concept. By combining the regional culture with the design theories, methods and technologies, the integration

\section{A. Expanding Curriculum Content}

In the curriculum setting of environmental design, colleges and universities can offer elective courses related to regional culture to introduce the origin, evolution, characteristics, connotation, innovation and development of regional culture to students. Special chapters can also be involved in the compulsory courses such as "Introduction of Environmental Art Design" and "History of Chinese and Global Architecture" to introduce the characteristics of residential environment, architectural culture and interior furnishing art of the region.

The teaching mode of "Bringing-In and Going-Out" can be applied. Besides the regular classroom teaching, local cultural scholars, folk intangible cultural heritage inheritors and other artists and experts can be invited regularly to hold special lectures for students in order to deepen their understanding and recognition of regional culture and broaden their horizons and thinking. At the same time, through organizing field investigations in practical teaching, the students could be led to perceive the regional architectural environment personally, experience folk culture and art, and get close contact with traditional skills. During the field investigation, a series of subjects such as pen sketch, spatial cognition training, surveying and mapping practice were integrated, and the regional culture was deeply explored in various forms such as interview, photo taking, video recording, surveying and mapping, which could help the students to have an intuitive and in-depth understanding of the regional residential culture while they were learning the basic design knowledge and skills. This could also help to stimulate the enthusiasm of students' research, inspire their design inspiration and enhance their humanistic connotation.

For example, the Jiashan Guangbiao Campus of our university is located in Jiashan, Zhejiang Province, adjacent to Xitang ancient town. The teaching team makes full use of this favorable condition and arranges a week every semester to lead students to Xitang for sketching. In the process of describing typical views such like small bridges over flowing water, house of whitewashed walls with black tile, the normal city life, etc., students also experienced the unique regional culture of waterbound town and the humanistic historical landscape in eastern China. In the course of environmental cognition practice, teachers organize students to investigate the layout of streets and lanes, waterfront space, ancient buildings in Ming and Qing Dynasties. The students were guided to observe record and sort out materials, and learn to extract abstract elements from concrete forms. This is very helpful for students when they take the follow-up professional courses, such as Chinese and Foreign Architectural History, Residential Space Transformation, New Chinese Style Restaurant Design and so on[3].

In addition, the role of information technologies in teaching should be given full play to integrate the resources of regional culture courses, build an open database of Chinese excellent regional culture, establish an open interactive teaching platform with students as the main body to arouses students' interest and participation in study, and cultivates innovative consciousness, 
for example, to integrate traditional teaching materials such as paper-based teaching materials, courseware, videos, etc. and spread through WeChat platform, website and other digital technologies so that students study independently and choose flexibly according to their needs.

\section{B. Optimizing Practice Teaching Design}

The cultivation of students' core competence in environmental design major is mainly accomplished through a series of design courses. Therefore, the integration of regional culture theme into the design courses can effectively guide students to learn from regional architecture and traditional settlements, search for the hidden features and make appropriate expression in the design process. This not only trains students' ability of conception, comprehensive analysis and design practice, but also enhances students' local design consciousness and original thinking. For example, in the course of interior design, local style restaurant design, folk art museum and other types of projects could be arranged to highlight the cultural research of interior space, while in the course of landscape design, renewal of the old community, reform of public green spaces in old districts, homestay design and other topics could be set to focus on the interpretation and inheritance of environmental context.

Around these representative topics, the practice teaching of design curriculum can be carried out in three stages: investigation and interpretation of regional culture, refining of concepts and elements, and explicit expression of design techniques[4]. In the first stage, by arranging certain forms of social survey, site survey and basic data collation, students are guided to pay attention to local design and regional culture, and are trained to master the methods of collecting and collating survey data. In the second stage, students are instructed to use data analysis, data visualization and other tools and methods to analyze the research data, complete the analysis of the base conditions and design tasks, master how to summarize the regional characteristics and refine the design concepts and elements from the environmental characteristics, native architecture, folk arts, clothing and utensils, folk festivals and other cultural forms, which helps to provide the basis and entry point for the next step design. In the third stage, students are trained to use abstract modeling techniques to transform concrete design elements into appropriate design languages and to complete the innovation process of "Understanding Exploring - Refining - Redesign" of regional culture. During the guidance process, teachers should always emphasize the principle of combining context with design, help students to deal with group relationship, spatial form and detail from the external conditions of culture, history, society and nature, consciously combine regional cultural characteristics with the times, organically combine local materials, traditional construction technology, traditional art language with modern design methods, materials and novel technologies such as sound, light, new media and so on, and finally create design works that not only have regional cultural charm, but also meet the needs of modern consumption experience and aesthetic needs.

Take the excellent graduation design work of 2019 of environmental design major of our university, Disappear \&
Regeneration - Chen Fang Qiao Neighborhood Park Design in Sheshan Town, Shanghai, as an example. The base of this project is located in Songjiang District, Shanghai, with two sides of the site facing the river and the southeast overlooking Sheshan Mountain. Used to be an important transportation station of Songjiang River, although Chen Fang Qiao had been out of the stage of history with the development of urban transportation, it still was the living memory of a whole generation. In order to retain people's memory of the past years as much as possible in the reconstruction project, the designer established the design concept of combining the historical context of the site with the modern landscape. Firstly, the designer deeply investigated and analyzed the environment and historical context of the site and collected data such as the characteristics and needs of the users. On this basis, the polyline elements are extracted from the "small fire wheel", which is a water transportation tool, and the sight corridor between the site and Sheshan Mountain. In the overall layout plan, the landscape spaces with different functional types were divided through the polyline spatial composition and the walking system and characteristic visual corridor were formed. All kinds of landscape facilities echo the form of "small fire wheel" in modeling, and complement each other with plants and water. The whole design scheme fully expresses the regional natural environment and historical and cultural characteristics, and creates a community park landscape with pleasant scale, twists and turns. From the perspective of this case, the "regional culture investigation and interpretation", "concept and element refining" and "explicit expression in design techniques" mentioned above are not only three teaching stages, but also a continuous process of design thinking. Among these three stages, the first one is fundamental. Therefore, teachers should try their best to put the design subject in the real regional environment, so that students can actually observe and experience and make it easier for students to construct a regional cultural framework and form a design concept integrated with regional characteristics.

\section{Developing multi-disciplinary teaching based on the concept of large design Macro Design}

In the 21st century, the field of environmental specialty has already broken through the traditional category of interior design. The subjects of the research and practice of environmental design ranges from as large as the planning of characteristic towns, the planning and design of urban water system and green system, the renewal and reconstruction design of old buildings, the micro renewal of city communities, down to the street furniture, sign system, signboards and commercial shop window. In addition, the demands of new life style led by various new technologies and new media for light environment, acoustic environment and space interaction also make the extension of environmental design expand continuously[5]. It can be said that environmental design covers almost all contemporary art and design. It is a comprehensive system of the art design, closely related to other disciplines such as visual communication art, digital media art, product design, etc. The society puts forward higher requirements for the knowledge structure, thinking mode and design ability of environmental design talents. Therefore, in the reform of professional teaching based on the concept of regional culture inheritance and innovation, we should break 
inheriting and innovating regional culture. On the one hand, to

the design category that each profession sticks to and cooperate to develop the curriculum design and workshop projects with regional culture theme and multi-disciplinary intersection with the target of joint and collaborative teaching. For example, with the theme of "tradition activation", "community building” and "rural reconstruction", etc., the interdisciplinary teaching teams of teachers and design groups of students were organized under a suitable project, targeting to solve a problem together. The regional culture was examined and interpreted from multiple perspectives in the fields of environmental design, product design, graphic design, digital media art and public art, and the regional humanities' visual elements were refined and summarized. And then through the way of design and art involved in society, the public space was reformed and environmental design works that meet the needs of people's better life were created while returning to tradition and preserving cultural memory[]. Through this kind of interdisciplinary practice teachi6ng, it is helpful to expand students' understanding of design, establish "macro design" thinking, experience the process of professional cross integration and collaborative innovation, and improve the awareness and ability of team cooperation.

\section{SUMMARY}

In the early 1990s, UNESCO held the "International Conference on Education for the 21st Century". The conference pointed out that focusing on the development of national and local characteristics of education is the general trend of the development of education in the world. This is a strategy to protect the multicultural education model in response to the singular cultural education model that may be brought about by global economic integration. As a training base for high-level environmental design talents, colleges and universities should be consciously responsible for spreading, flexible use of expert lectures, case studies, field visits, project practice, cross-professional collaborative teaching and other teaching forms can improve teachers and students' cultural and artistic literacy and social service awareness, guide students to absorb nutrition from regional culture and actively explore the redesign of traditional culture and art, so as to effectively cultivate high-quality and innovative local design professionals. On the other hand, the organic integration of regional culture into teaching, scientific research, and design practice is conducive to consolidating the professional characteristics of environmental design, and then creating a brand specialty based on regional culture.

\section{REFERENCES}

[1] C. Zhang, "From the Perspective of ZhongYuan Folk Art Analysis of the Teaching Architecture Space Design”, Design, 2013, No.8, pp.86-88. (In Chinese)

[2] K. Chen, "Research on Environmental Art Design Education in Higher Vocational Colleges under the Regional Culture Field”, Journal of Guangdong Agriculture Industry Business Polytechnic, 2017, No.2, pp.44-46+83. (In Chinese)

[3] H.O. Wang, "Practical teaching by combining regional culture with architecture courses”, Journal of University of Science and Technology Liaoning, 2013, No.3, pp.240-243. (In Chinese)

[4] T.Y. Zhang, Z.R. Wang, "Integration of Regional Concept into Architectural Teaching Design for Applied Undergraduates”, Architecture \& Culture, 2018, No.11, pp.176-177. (In Chinese)

[5] Y. Lou, "New Environmental Design in the Global Knowledge Internet Time”, Journal of Nanjing Arts Institute (Fine Arts \& Design), 2017, No.1, pp.3-9+224. (In Chinese)

[6] S. Ma, "Research on the Teaching Reform of Environmental Design Course Based on Inheriting Regional Humanistic Factors”, Art Science and Technology, 2019, No.10, p.49. (In Chinese) 